\title{
FAKTOR PEMBENTUK HARAPAN WISATAWAN; SEBUAH PERSPEKTIF LINTAS BUDAYA (STUDI PADA WISATAWAN PERANCIS, AUSTRALIA, DAN NUSANTARA YANG BERKUNJUNG DI PULAU LOMBOK)
}

\author{
B. Handayani R. ${ }^{1}$ \\ H. Rusdan ${ }^{1}$ \\ H. Junaidi Sagir ${ }^{1}$
}

\begin{abstract}
This research aimed to determine the modifier factors of the Australian, France and Indonesian (Nusantara) tourist hope toward Lombok Island, and explain the relation between cultural background of each group according to Hofstede theory and the modifier factors. Method that used in this research was descriptive method with the sample survey approach. Sample for each group was 50 persons. The data were analyzed by descrip tive analyze and statistic analyze by using factor analyze. The result shown the Australian with have individualistic culture background was forming the hope dominated by past experience, the France tourist, with uncertainty avoidance culture background, was forming their hope by collecting external information, while Indonesian with their collectivities culture tend to form their hope base on word of mouth. The difference of hope modifier in each tourist group became important thing to payed by the tourist executants to determine the tourism marketing strategy in the future.
\end{abstract}

Keywords : Hope, Hofstede Culture, Past Experience, External Information, Destination Image, Word of Mouth

\section{Latar Belakang}

Harapan merupakan faktor penentu kepuasan konsumen (Kotler \& Keller, 2006). Dan memiliki peranan yang besar sebagai standar perbandingan dalam evaluasi terhadap produk yang dikonsumsi maupun stimuli awal yang mengarahkan perilaku konsumen dalam menentukan keputusan membeli suatu produk. Menurut Olson dan Dover (dalam Zeithaml et al., 1993) harapan pelanggan merupakan keyakinan pelanggan sebelum mencoba atau membeli suatu produk, yang dijadikan standar atau acuan dalam menilai kinerja produk tersebut.

Dalam konteks pemasaran pariwisata, memahami harapan wisatawan merupakan sesuatu yang sangat penting karena harapan secara signifikan dapat memengaruhi proses pilihan wisata serta pengalaman yang akan dirasakan (Gnoth, 1997). Bosque, Martin, Collado, \& Salmones (2009)

Wisatawan berkunjung dan memasuki suatu daerah dengan latar belakang kehidupan yang selama ini membentuk perilaku dan menjadi karakteristik mereka. Meskipun mereka bertemu, berinteraksi tidak hanya dengan wisatawan dari negara lain, tetapi juga dengan penduduk lokal dengan suasana yang jauh berbeda dengan negara asalnya, perilaku yang sudah terbentuk lama tidak begitu saja mereka lepaskan. Perbedaan bahasa, cara berpakaian, cara makan, pandangan, gaya hidup, dan berbagai aktivitas yang dilakukan banyak ditemukan diantara wisatawan. Budaya adalah faktor yang memiliki pengaruh paling luas terhadap banyak dimensi dari perilaku manusia. Individu dari budaya yang berbeda akan memiliki nilai budaya, aturan perilaku sosial, persepsi, dan interaksi sosial yang berbeda, yang selanjutnya akan memengaruhi gaya hidup, pola kerja, cara bersantai, dan pola perilaku konsumsi mereka (Richardson, 1988 dalam Meng, 2010). Dengan demikian perbedaan budaya antar wisatawan akan menghasilkan perbedaan sikap, opini, emosi, dan kecenderungan untuk melakukan pembelian (Reseinger, 2009).

Sebagai salah satu daerah tujuan wisata (DTW), Pulau Lombok dengan berbagai kekhasan dan potensi yang dimiliki, telah berkembang dan cukup diperhitungkan di tingkat

\footnotetext{
${ }^{1}$ Staf Pengajar MM UNRAM
} 
Nasional maupun Internasional (Visit, 2012). Meskipun demikian, kepedulian dan komitmen pemerintah NTB, pelaku pariwisata, dan masyarakat dalam menjaga dan meningkatkan kondisi ini senantiasa harus dilakukan dalam upaya meningkatkan kunjungan wisatawan. Wisatawan yang berkunjung ke Provinsi Nusa Tenggara Barat (NTB), meliputi wisatawan mancanegara maupun wisatawan dalam negeri.

Berdasarkan data Dinas Kebudayaan dan Pariwisata NTB jumlah wisatawan mancanegara yang berkunjung berdasarkan kebangsaan pada tahun 2012, Perancis dan Australia merupakan negara asal wisatawan terbanyak yang berkunjung. Disamping wisatawan mancanegara, kunjungan wisatawan Nusantara juga memiliki kontribusi penting bagi perkembangan ekonomi pada daerah tujuan wisata, terlebih lagi wisatawan Nusantara memiliki kemungkinan yang cukup besar untuk melakukan perjalanan wisata di dalam negeri. Sebagai pasar potensial kunjungan wisatawan dari ketiga negara tersebut perlu dipertahankan dan ditingkatkan. Berdasarkan kenyataan tersebut diperlukan adanya kajian menyangkut faktor-faktor pembentuk harapan wisatawan dengan latar belakang budaya Nasional berbeda guna mempermudah para pelaku industri pariwisata dalam mengontrol harapan wisatawan dan meningkatkan pengalaman serta kepuasan wisatawan selama berkunjung.

Berdasarkan latar belakang tersebut permasalahannya dapat dirumuskan sebagai berikut: (1) Faktor apa saja yang membentuk harapan wisatawan pada kelompok wisatawan mancanegara dan wisatawan nusantar, (2) Bagaimana keterkaitan faktor pembentuk harapan kelompok wisatawan dengan latar belakang budaya nasional mereka. Dengan demikian penelitian ini bertujuan untuk menentukan faktor pembentuk harapan wisatawan Perancis, Australia dan wisatawan Nusantara terkait dengan Pulau Lombok serta memahami keterkaitan faktor pembentuk harapan wisatawan dengan latar belakang budaya setiap kelompok wisatawan.

\section{Tinjauan Teoritis}

\subsection{Penelitian Terdahulu}

Penelitian terdahulu terkait penentuan sumber pembentuk harapan wisatawan belum banyak dilakukan. Penelitian yang dilakukan selama ini lebih menekankan pada hubungan harapan terhadap kepuasan wisatawan (Sivesan \& Thusyantini, 2013; Nnanjar, 2012, Jadhav \& More, 2010). Penelitian Nael (2010) membuktikan adanya hubungan nilai budaya dengan kualitas pelayanan, harapan, persepsi, dan niat berperilaku. Hasil beberapa penelitian tersebut menunjukkan bahwa harapan wisatawan menjadi salah satu faktor penting yang perlu diperhatikan dalam perilaku wisatawan, sehingga diperlukan pengelolaan terhadap harapan wisatawan. Lather, Singh dan Singh (2010) melakukan penelitian yang bertujuan mengeksplorasi perbedaan tingkat harapan dan kepuasan dari wisatawan India dan mancanegara (luar negeri), demikian pula Aksu, Icigen, dan Ebtiyar (2010), meneliti hal yang sama pada wisatawan yang berkunjung ke Antalya (Turki). Temuan yang diperoleh kedua penelitian tersebut membuktikan adanya perbedaan harapan dan tingkat kepuasan diantara wisatawan.

Gnoth (1997), Bosque et al. (2009), Bhat dan Qadir (2013) melakukan penelitian untuk berkontribusi dalam membangun model sumber pembentuk harapan dengan memberikan 'bukti teoritis dan empiris tentang peran faktor yang berbeda yang menghasilkan harapan wisatawan. Hasil yang diperoleh menunjukkan harapan wisatawan terbentuk oleh pengalaman pribadi, komunikasi eksternal, WOM, dan image destinasi, dimana image destinasi merupakan sumber terpenting pembentuk harapan wisatawan. Penelitian ini menyarankan pula bagi peneliti selanjutnya untuk mengembangkan eksplorasi pembentukan harapan pada berbagai kelompok wisatawan menurut kebangsaan mereka.

\subsection{Landasan Teori}




\subsubsection{Harapan}

Harapan akan timbul saat konsumen memerlukan suatu barang atau jasa. Menurut Hill (1992:45) harapan adalah, apa yang konsumen pikirkan harus disediakan oleh penyedia jasa. Akan tetapi, harapan bukan merupakan prediksi dari apa yang akan disediakan oleh penyedia jasa. Menurut teori harapan yang dikembangkan oleh Vroom (Vroom's Expectancy Model) pada umumnya manusia memilih salah satu di antara beberapa alternatif perilaku karena manusia tersebut melakukan antisipasi yang secara khusus akan membawa seseorang kepada hasil sesuatu yang diinginkan (Allen, 1998). Dalam hal ini harapan (expectacy) dipercaya sebagai sesuatu yang diinginkan untuk mendapatkan hasil yang maksimal atas perilaku yang dipilih.

Pada penilaian kualitas produk maupun jasa harapan konsumen memiliki peranan yang besar sebagai standar perbandingan dalam evaluasi kualitas maupun kepuasan. Untuk membuktikan apakah kualitas produk baik atau tidak, dapat diukur dari tingkat kepuasan konsumen. Kepuasan konsumen terhadap suatu jasa adalah perbandingan antara persepsi konsumen terhadap jasa yang diterima dengan harapannya sebelum menggunakan jasa tersebut. Apabila harapannya terlampaui, berarti jasa tersebut telah memberikan suatu kualitas yang luar biasa dan juga akan menimbulkan kepuasan yang sangat tinggi, dan sebaliknya. Dalam konteks pariwisata, mengelola harapan wisatawan adalah sangat penting, karena harapan secara signifikan dapat memengaruhi proses pilihan wisata serta persepsi pengalaman (Gnoth, 1997), dan berimplikasi pada daerah tujuan wisata.

\subsubsection{Faktor-faktor Pembentuk Harapan}

Menurut Horovitz (2000:8), harapan konsumen dapat terbentuk oleh empat faktor, antara lain : (1) Kebutuhan, (2) Media, (3) Pengalaman masa lalu, dan (4) Mulut ke mulut (word of mouth). Beberapa ahli mengemukaan hal berbeda terkait sumber pembentuk harapan (Oliver, 1987; Prakash dan Lounsbury, 1984), dan belum tercapai kesepakatan mengenai sifat standar harapan yang spesifik, jumlah standar yang digunakan, maupun sumber harapan (Iqbal, 2012). Terkait dengan pariwisata dari berbagai penelitian tentang harapan wisatawan, penelitian Santos dan Boote (2003) menunjukkan bahwa faktor pengalaman masa lalu, komunikasi eksternal, komunikasi word of mouth, dan image destinasi menjadi pembentuk harapan wisatawan. Hasil penelitian tersebut seringkali digunakan sebagai rujukan dalam menganalisis sumber pembentuk harapan wisatawan.

\subsubsection{Budaya dan Budaya Hofstede}

Menurut Taylor (1871) dalam Reisinger (2009); Reisinger dan Turner (2003) budaya adalah sebuah kesatuan yang kompleks yang mencakup pengetahuan, keyakinan, seni, moral, adat istiadat, dan kemampuan serta kebiasaan lain yang didapatkan manusia sebagai anggota dari masyarakat. Dalam penelitian lintas budaya, budaya biasanya dipahami sebagai sebuah watak budaya yang stabil dan dominan dari sebuah masyarakat yang berlaku bagi sebagian besar individu di dalam masyarakat itu dan bertahan secara konstan untuk periode waktu yang panjang (Reisinger, 2009). Budaya mempunyai pengaruh yang kuat terhadap perilaku konsumen (Schiffman \& Kanuk, 2007) dan penentu fundamental dari keinginan dan perilaku seseorang (Kotler, 2003). Perbedaan budaya antar wisatawan akan menghasilkan perbedaan sikap, opini, emosi, (Reseinger, 2009), nilai budaya, aturan perilaku sosial, persepsi, dan interaksi sosial yang berbeda, yang selanjutnya akan mempengaruhi gaya hidup, pola kerja, cara bersantai, dan pola perilaku konsumsi mereka (Richardson, 1988 dalam Meng, 2010). Kerangka budaya Hostede adalah kerangka budaya nasional yang paling banyak digunakan dalam penelitian psikologi, sosiologi, pemasaran atau manajemen (Sondergaard, 1994; Steenkamp, 2001; dalam Soares 2007). Adapun Dimensi budaya Hofstede terdiri atas:

1. Dimensi Jarak kekuasaan. Mencerminkan sejauh mana kelompok masyarakat yang lebih lemah (less power) dalam suatu kultur menerima ketidakadilan dan ketimpangan dalam hal distribusi kekuasaan sebagai situasi normal. 
2. Dimensi individualisme - kolektivisme, merefleksikan sejauh mana individu dalam suatu budaya menempatkan kepentingan pribadinya dibandingkan kepentingan keluarga dekat dan kelompok sosial lainnya.

3. Dimensi Penghindaran ketidakpastian. merefleksikan sejauh mana masyarakat dalam suatu budaya merasa terancam dengan situasi yang penuh ketidakpastian, tidak bisa diprediksi dan tidakjelas.

4. Dimensi maskulinitas-feminitas, merupakan nilai dominan masyarakat yang menekankan ketegasan/sikap asertif dan uang yang diperoleh serta barang material lain.

5. Orientasi jangka panjang, mengacu pada sejauh mana suatu budaya memiliki perspektif pragmatis jangka panjang a tau orientasi jangka pendek historis.

\section{Metode Penelitian}

Metode yang digunakan dalam penelitian ini adalah metode deskriptif dengan menggunakan pendekatan sampel survey. Data dikumpulkan melalui kuesioner, yang diberikan secara langsung kepada wisatawan Perancis, Australia, dan Indonesia yang sedang melakukan wisata di P.Lombok. Populasi dalam penelitian ini adalah seluruh wisatawan Perancis, Australia dan Nusantara yang sedang berkunjung di Pulau Lombok. Berdasarkan pertimbangan luasnya wilayah, dan banyaknya jumlah wisatawan, maka teknik sampling yang digunakan adalah purposive sampling, dan focus pada kawasan Senggigi, Gili Trawangan, Pantai Kuta, dan pantai Pink, dengan pertimbangan konsentrasi kegiatan kepariwisataan yang lebih besar dan lebih banyak. Jumlah responden dalam penelitian ini sebanyak 50 orang tiap kelompok dan ditentukan secara purposive sampling . Variabel yang akan dianalisis meliputi:

a. Pengalaman masa lalu, yakni apa yang dirasakan wisatawan sebagai hasil menikmati perjalanan sebelumnya di P.Lombok yang diutarakan dalam bentuk setuju-tidak setuju.

b. Komunikasi eksternal yakni penilaian wisatawan akan informasi yang diterima tentang P.Lombok melalui berbagai sumber, yang diutarakan dalam dalam bentuk setuju-tidak setuju.

c. Word Of Mouth (WOM) yakni informasi tentang P.Lombok yang diperoleh dari komunikasi dengan kerabat, teman, atau orang yang dikenal, yang diutarakan dalam bentuk setuju-tidak setuju.

d. Image destinasi yakni berbagai kesan yang diperoleh tentang P.Lombok, yang diutarakan dalam bentuk setuju-tidak setuju.

Adapun tahapan analisis yang dilakukan meliputi:

1. Penentuan faktor pembentuk harapan dengan Analisis Faktor

Model analisis faktor menurut Sharma (1996):

$$
\begin{array}{cc}
\mathrm{Fi}=W \mathrm{Wi}_{1} \mathrm{X}_{1}+\mathrm{Wi}_{2} \mathrm{X}_{2}+\mathrm{Wi}_{3} \mathrm{X}_{3}+\ldots \ldots \ldots \ldots \ldots+\mathrm{Wi}_{\mathrm{k}} \mathrm{X}_{\mathrm{k}} \\
\text { Dimana: } & \mathrm{Fi}=\text { estimasi faktor ke }-\mathrm{i} \\
& \mathrm{Wi}=\text { bobot atau koefisien niali faktor } \mathrm{ke}-\mathrm{i} \\
\mathrm{k}=\text { jumlah variabel } \\
\mathrm{X}_{\mathrm{i}}=\text { variabel ke }-\mathrm{i},
\end{array}
$$

2. Analisis Kualitatif yang bertujuan menjelaskan keterkaitan hasil analisis faktor pada setiap kelompok wisatawan dengan latar belakang budaya tiapkelompok. Pendekatan pengukuran budaya dilakukan menggunakan inferensi nilai tidak langsung (benchmark), yaitu menggunakan data sekunder (Skor budaya Nasional Hofstede) untuk menentukan karakteristik dari kelompok-kelompok budaya tanpa melakukan pengukuran secara langsung terhadap anggota dari kelompok

\section{Hasil dan Pembahasan}


Beberapa asumsi yang diperlukan dalam melaksanakan analisis faktor meliputi penentuan Kaiser-Meyer-Olkin (KMO) dan Barlett's test. Hasil perhitungan KMO dan Barlett's test tiap kelompok ditunjukkan pada Tabel 1 berikut ini:

Tabel.1

KMO and Bartlett's Test Responden Australia, Perancis, dan Nusantara

\begin{tabular}{llrrr}
\hline & & $\begin{array}{c}\text { AUSTRALI } \\
\text { A PERANCIS }\end{array}$ & NUSANTAR \\
& & \multicolumn{1}{c}{ A } & & \multicolumn{1}{c}{ A } \\
\hline & Kaiser-Meyer-Olkin Measure & 0.599 & 0.664 & 0.726 \\
of Sampling Adequacy. & & & \\
Bartlett's Test & Approx. Chi-Square & 1404.711 & 1310.847 & 1448.166 \\
of Sphericity & Df & 378 & 378 & 378 \\
& Sig. & .000 & .000 & .000 \\
\hline
\end{tabular}

Sumber : Data Primer diolah

Nilai KMO yang ditunjukkan dari hasil analisis faktor pada ketiga kelompok menunjukkan nilai > 0,50. menerangkan bahwa ke-28 item penjelas harapan wisatawan sudah memiliki interdependensi yang tinggi. Barlett's Test of Sphericity pada hasil tiap kelompok menunjukkan angka signifikansi 0,000 yang berarti antar variabel terjadi korelasi sehingga dapat disimpulkan bahwa variabel dan sampel sudah layak untuk dianalisis lebih lanjut.

Pada kelompok wisatawan Australia, ekstraksi faktor membentuk tujuh komponen dengan kontribusi sebesar 78,617\% dalam menjelaskan keragaman harapan wisatawan. Komponen pertama menyumbang $36,473 \%$ dan item-tem yang mewakili sebagian besar adalah pengalaman masa lalu dan citra destinasi. Komponen kedua menyumbang 16,025\% dan item yang mewakili sebagian besar adalah komunikasi eksternal dan word of mouth. Sedangkan komponen ketiga menyumbang $6,529 \%$ dan item yang mewakili sebagian besar adalah item citra destinasi. Jumlah kumulatif keragaman total yang dijelaskan oleh tiga komponen pertama adalah 59,027\% (hampir 60\%). Sehingga hasil analisis ini memberikan gambaran bahwa struktur data harapan wisatawan Australia secara berurutan lebih banyak berkaitan dengan pengalaman masa lalu, komunikasi eksternal dan citra destinasi.

Berdasarkan karakteristik dari lima dimensi Budaya Hofstede tersebut sebagai negara yang berorientasi pada individualisme (90), maskulin (), penghindaran ketidakpastian sedang (), jarak kekuasaanrendah 0 dan orientasi jangka panjang rendah (), mengindikasikan orientasi pada penghargaan pada independensi, pemenuhan tujuan pribadi, keberhasilan, kepercayaan pada diri sendiri yang tinggi, serta komitmen jangka pendek menjadi nilai dominan yang membentuk keyakinan anggota masyarakat di negara tersebut.

Individu yang berasal dari latar belakang budaya tersebut menekankan kepada kebebasan dan sangat mementingkan tujuan pribadi, lebih termotivasi oleh preferensi diri termasuk kebutuhan dan hak diri, memberikan prioritas terhadap tujuan pribadi, dan memiliki fokus terhadap analisa rasional dari hubungan mereka dengan orang lain (Triandis, 1989), serta memiliki rasa interdependen (saling tergantung) yang cenderung rendah (Hofstede, 1991). Preferensi dan kepentingan akan pemuasan kebutuhan diri sendiri mendorong seseorang untuk cenderung membentuk harapannya akan suatu obyek berdasarkan pengalaman yang sudah dirasakan sebelumnya dan mengutamakan apa yang telah mereka rasakan sendiri. Dorongan untuk selalu mendapatkan hasil terbaik dan tingkat kepercayaan diri yang kuat mengakibatkan wisatawan Australia cenderung lebih yakin dengan a pa yang mereka rasakan pada pengalaman sebelumnya, sehingga harapan pada destinasi lebih dominan dibentuk oleh faktor tersebut. Kepuasan yang dirasakan pada pengalaman sebelumnya akan membentuk harapan positif atas obyek yang 
dikonsumsi, dan akan mengarahkan perilaku wisatawan untuk melakukan kunjungan ulang pada destinasi tersebut.

Pada kelompok wisatwan Perancis Ekstraksi faktor membentuk delapan komponen dengan kontribusi sebesar 82,589\% dalam menjelaskan keragaman harapan wisatawan. Komponen pertama menyumbang 33,068\% dan item-tem yang mewakili sebagian besar adalah komunikasi eksternal dan citra destinasi. Komponen kedua menyumbang 14,735\% dan item yang mewakili sebagian besar adalah citra destinasi. Sedangkan komponen ketiga menyumbang 9,277\% dan item yang mewakili sebagian besar adalah pengalaman masa lalu. Jumlah kumulatif keragaman total yang dijelaskan oleh tiga komponen pertama adalah 57,080\% (hampir 60\%). Sehingga hasil analisis ini memberikan gambaran bahwa struktur data harapan wisatawan Perancis secara berurutan lebih banyak berkaitan dengan komunikasi eksternal, citra destinasi dan pengalaman masa lalu.

Latar belakang budaya Perancis berdasarkan kelima dimensi budaya Hofstede memiliki skor jarak kekuasaan yang cukup tinggi (68), individulis tinggi (71), penghindaran ketidakpastian tinggi (86), feminin (43), dan orientasi jangka panjang tinggi (63). Berdasarkan karakteristik tersebut dan terkait dengan faktor dominan yang membentuk harapan wisatawan Perancis, menunjukkan keterkaitan dimensi budaya penghindaran ketidakpastian pada kelompok wisatawan tersebut.

Penghindaran ketidakpastian merefleksikan sejauh mana masyarakat dalam suatu budaya merasa terancam dengan situasi yang penuh ketidakpastian, tidak bisa diprediksi dan tidak jelas. Penghindaran ketidakpastian melibatkan tingkat perasaan tidak nyaman dengan lingkungan yang tidak pasti dan ambigu. Mereka berupaya sedemikian rupa untuk mengurangi kemungkinan resiko yang akan didapat dari perilaku atau tindakan yang dipilih.tersebut. Penghindaran ketidakpastian yang tinggi pada kelompok tersebut mendorong mereka untuk mendapat informasi dari sumber resmi, handal dan dapat dipercaya. Informasi yang diperoleh dari pihak eksternal diyakini dapat membantu wisatawan pada saat melakukan perjalanan dan dapat sedini mungkin mengantisipasi segala kemungkinan atau resiko yang mungkin akan didapatkan dalam perjalanan tersebut. Walaupun pada kelompok wisatawan Perancis dilatar belakangi oleh budaya individualisme yang cukup tinggi, namun orientasi budaya feminin dan jarak kekuasaan yang cukup tinggi menjadikan individu dari negara tersebut cenderung lebih mengutamakan pembentukan harapan dari sumber eksternal, citra destinasi, dan pengalaman masa lalu.

Pada Kelompok wisatwan Nusantara ekstraksi faktor membentuk delapan komponen dengan kontribusi sebesar 86,063\% dalam menjelaskan keragaman harapan wisatawan. Komponen pertama menyumbang 39,416\% dan item-tem yang mewakili sebagian besar adalah word of mouth. Komponen kedua menyumbang 10,893\% dan item yang mewakili sebagian besar adalah pengalaman masa lalu. Sedangkan komponen ketiga menyumbang 8,243\% dan item yang mewakili sebagian besar adalah item citra destinasi. Jumlah kumulatif keragaman total yang dijelaskan oleh tiga komponen pertama adalah 58,552\% (hampir 60\%). Sehingga hasil analisis ini memberikan gambaran bahwa struktur data harapan wisatawan nusantara secara berurutab lebih banyak berkaitan dengan word of mouth, pengalaman masa lalu dan citra destinasi.

Berdasarkan dimensi budaya Hofstede, Indonesia menunjukkan skor tinggi pada dimensi jarak kekuasaan (78), kolektivis (14), penghindaran ketidakpastian yang pragmatis (48), feminin (46), dan orientasi jangka panjang yang tinggi (62). Orientasi budaya yang melatarbelakangi wisatawan Nusantara tersebut tentunya dapat berpengaruh pada bagaimana wisatawan membentuk harapan mereka terhadap destinasi yang akan dikunjungi. Dari hasil analisis faktor menunjukkan pembentuk harapan wisatawan Nusantara terutama berasal dari word of mouth yakni pendapat yang baik atau positif tentang Pulau Lombok dari kerabat atau orang yang dikenal. Sebagai masyarakat dengan tingkat kolektivis tinggi yang ditunjukkan dengan sikap kekeluargaan dan mengutamakan harmonisasi dan kelompok, pendapat keluarga, teman atau orang-orang terdekat menjadi sumber utama yang membentuk persepsi dan harapan wisatawan. Mereka cenderung lebih percaya pada informasi yang disampaikan dari pihak yang mereka telah kenal dengan baik sebagai bagian dari 
kelompok dan sangat mengutamakan kebersamaan atau harmonisasi dalam kelompok. Keinginan untuk merasakan hal yang sama dengan anggota kelompok lain serta berupaya memelihara keutuhan kelompok menjadikan individu dari budaya dengan tingkat kolektivisme tinggi sangat setia pada kemauan kelompok, Apa yang diyakini oleh salah satu anggota kelompok atau keluarga akan dapat memengaruhi persepsi, sikap dan keyakinan anggota kelompok lainnya. Dengan demikian apa yang dianggap baik oleh kelompok cenderung akan dianggap baik oleh semua anggota kelompok

\section{Simpulan dan Saran}

Berdasarkan uraian tersebut menunjukkan adanya perbedaan sumber pembentuk harapan wisatawan pada tiap kelompok berdasarkan latar belakang budaya. Oleh karena itu perlu bagi para pelaku pariwisata untuk berupaya sedemikian rupa dalam membentuk harapan yang positif terhadap destinasi Pulau Lombok. Wisatawan Australia yang cenderung membentuk harapannya berdasarkan pengalaman sebelumnya hendaknya mendapatkan kepuasan pada perjalanan sebelumnya. Pelayanan yang berkualitas, kermahtamahan penduduk, sarana dan prasarana pendukung yang berkualitas, serta atraksi budaya dan keindahan alam sedapat mungkin dikelola dengan baik sehingga dapat memenuhi harapan wisatawan.

Wisatawan Perancis dengan latar belakang penghindaran ketidakpastian yang cenderung tinggi, lebih berhati-hati dalam mengambil keputusan. Informasi eksternal yang berasal dari lembaga atau organisasi resmi dan diyakini handal lebih besar kemungkinan untuk membentuk harapan mereka. Hal ini tentunya menjadi salah satu saluran komunikasi yang dapat digunakan pemerintah dan pelaku wisata dalam memberikan informasi yang handal terkait dengan Pulau Lombok. Menjalin dan memelihara hubungan yang baik dengan berbagai agen dan biro perjalanan, menggiatkan pameran dan promosi luar negri, serta memiliki situs dan web resmi terkait pariwisata di Pulau Lombok akan menjadi sumber yang dapat membentuk harapan wisatawan Perancis, sehingga semakin mendorong minat mereka untuk berkunjung ke Pulau Lombok.

Kunjungan wisatawan Nusantara sebagai wisatawan domestik memberikan makna yang berarti bagi perkembangan destinasi Pulau Lombok. Sebagai masyarakat dengan tingkat kolektivitis tinggi, pendapat teman, kerabat dan orang yang dikenal disekitar mereka memberikan pengaruh yang cukup berarti dalam pembentukan harapan wisatawan. Oleh karena itu memberikan pelayanan yang berkualitas dan kepuasan kepada wisatawan domestik yang berkunjung menjadi kunci sukses dalam meningkatkan minat kunjungan wisatawan domestik lainnya. Dengan informasi dan rekomendasi dari orang-orang yang telah dikenal disekitarnya akan memberikan peluang bagi peningkatan jumlah wisatawan yang memilih Pulau Lombok sebagai destinasi utama pilihan mereka.

\section{Daftar Pustaka}

Aksu,Akin, Icigen,Ebru, Ehtiyar, Riiya, 2010, A Comparison of Tourist Expectations and Satisfaction: A Case Study from Antalya Region of Turkey, Journal TURIZAM, Volume $\quad$ 14, Issue 2, 66-77 (2010) 77

Allen, G. (1998). Hyperlink Book: Supervision, gemmyallen@dcccd.edu.

Anonim, Statistik Kebudayaan dan Pariwisata Provinsi Nusa Tenggara Barat Tahun 2012, Dinas Kebudayaan dan Pariwisata Provinsi Nusa Tenggara Barat

Bhat, Ahmad Mushtaq, Qadir,Nabina, 2013, An Emperical Assessment of Tourists' Expectations and Perceptions, International Journal of Applied Services Marketing Perspectives, Volume 2, Number 2, April-June 2013 
Bosque, Ignacio Rodriguez, Martin, Hector San, Collado, Jesus, and Salmones, Maria del Mar Garcia, 2009, A Framework for Tourist Expectations, International Journal of Culture, Tourism, and Hospitality Research, Vol. 3 NO. 2 , Emerald Group Publishing Limited

Gnoth, Juergen, 1997, Tourism, Motivation and Expectation Formation, Annals of Tourism Research, Vol. 24, No. 2 , Elsiver Science, Ltd.

Hill, A.V. (1992). Field Service Management. Illinois: Richard D. Irwin, Inc.

Horovitz, J. (2000). Seven Secrets Of Service Strategy Great Britain: Prentice Hall.

Hoftstede, Geert, 1991, Cultures and Organizations, Software of the Mind, McGraw-Hill, New York.

Hofstede, 2011, Dimensionalizing Cultures : The Hofstede Model in Context, Online Reading in Psychology and Culture, Unit 2. Retrieved from http://scholarworks.gvsu.edu/orpc/vol2/iss1/8

Iqbal, Mohamad, 2012, Pengaruh Persepsi Nilai, Harapan, dan Kepercayaan Terhadap Kepuasan Konsumen pada Penyedia Jasa Internet di Jabodetabek, Jurnal Kepuasan Konsumen, Universitas Guna darma

Jadhav,S.J., More,V.S., (2010), Coverage of Maximum Destinations: General Expectations of Tourists, International Refereed Research Journal, Vol.- I, Issue -1,October 2010

Kotler, Keller, 2006, Marketing Management, Twelfth Edition, Prentice Hall

Meng, Fang, 2010, Individualism/ Coolectivism and Group travel Behavior : a Cross- cultural Perspective, International Jornal of Culture, Tourism, and Hospitality Research

Nnanjar, Gertrude, 2012, Analysis of the Relationships between Tourists' Expectation of Heritage Attributes and Satisfaction in the Cross River State Carnival Festival, Nigeria, Journal Planning, Environment and Tourism

Nuray, Li, Uysal, 2012, Cross Cultural Differences in Purchase Decision Marketing Criteria, International Journal of Culture, Tourism and Hospitality Research

Oliver, R.L. (1997), Satisfaction: A Behavioral Perspective on the Consumer, MoGraw-Hill, New York, NY.

Pizam-Abraham, Jeong Gang-Hoan, 1996, Cross-Cultural Tourist Behavior; Perception of Korean Tour-Guides, Journal Tourism Management, Vol 17. Nop 4. Pp 277-289

Reisinger, Turner, 2003, Cross-Cultural Behaviour in Tourism ; Concept and Analysis, Butterwoth Heinemann $(\mathrm{BH})$

Reisinger, Yvette, 2009, Cross-Cultural Differences in Tourist Behavior,Handbook of Tourist Behavior, Theory \& Practice, Routledge; Taylor \& Francis Group: New York- London

Santos, J. and Boote, J. (2003), "A theoretical exploration and model of consumer expectations, postpurchase affective states and affective behaviour", Journal of Consumer Behaviour, Vol. 3 No. 2, pp. 142-56.

Schifman, Leon, Kanuk, 2007, Consumer Bahavior,7thEd, Kasip, Zoelkifli （penerjemah), Perilaku Konsumen, Edisi Ketujuh, Indeks, Jakarta

Sharma, Subhash, 1996, Applied Multivariate Techniques, John Wiley \& Sons, Inc NewYork.

Sherif, M. and Hovland, C.I. (1961), Social Judgment: Assimilation and Contrast Effects in Communication and Attitude Change, Yale University Press, New Haven, CT.

Sivesan, S, Thusyanthini, 2013, Perceptions with Reference to Heritages Attributes of Sri Lanka,Industrial Engineering Letters Vol.3, No.10, 2013

Soares, Farhangmehr, Shoham, 2007, Hofstede's Dimensions of Culture in International Marketing Studies, Journal of Business Research 60 (2007) 277 -284

Triandis, CH, 1989, The Self and Social Behavior in Differing Cultural Contexts, Psychological Review.

Visit ; Citra Budaya Pariwisata, Edisi 01/2012, Dinas Kebudayaan dan Pariwisata NTB dan Media Lombok Mandiri

Yu Ji-Yun, Gyou Ko Tae, 2012, A cross-cultural study of perceptions of medical tourism among Chinese, Japanese and Korean tourists in Korea, Journal Tourism Management 33 (2012) 80e88

Zeithaml, V.A., Berry, L. L. and Parasuraman, A. (1993), "The nature and determinants of customer expectations of service", Journal of the Academy of Marketing Science, Vol. 21 No. 1, pp. 112. 